\title{
Reflexiones sobre Inteligencia Artificial y Radiología
}

\section{Juan Pablo Cruz Quiroga'*}

1. Radiólogo. Pontificia Universidad Católica de Chile. Santiago, Chile.

La inteligencia artificial (IA) viene como un fuerte polo de desarrollo e innovación en múltiples áreas del quehacer humano. Es así como una de sus variantes, el "natural language processing", ha mostrado ser capaz de hacer mejores contratos que algunos abogados y revisar mejor las leyes que algunos legisladores. Términos como "Deep learning" y "neural networks" aparecen cada vez con mayor frecuencia en publicaciones relacionadas con análisis de imágenes y con el rendimiento diagnóstico de estudios de los cuáles los radiólogos nos dedicamos a interpretar. Áreas como la radiomica (el cruce entre parámetros o datos de imágenes se cruzan con expresión o mutación de ciertos genes) han aumentado su relevancia y potencial aplicación clínica gracias a las técnicas de inteligencia artificial que permiten procesar y analizar grandes cantidades de datos, encontrando correlaciones entre variables que pueden no ser aparentes al análisis hecho por humanos.

En el último tiempo ha vuelto el interés por el diagnóstico asistido por computador (DAC), el que en la década de los 90 no logró establecerse en el uso rutinario de imágenes con la fuerza que se predijo inicialmente. Las nuevas técnicas de proceso y las mayores capacidades de manejo grandes cantidades de datos de los equipos actuales han devuelto el entusiasmo por el DAC. En esta vuelta, como en otras ocasiones "revoluciones tecnológicas", se ha creado un ambiente de temor en nuestra disciplina por el miedo a ser reemplazados en nuestro quehacer por computadores que sean capaces de hacerse cargo de la interpretación e incluso de la elaboración de informes radiológicos. Declaraciones como las aportadas en el NEJM el 2016, en que se decía que "el machine learning reemplazará mucho del trabajo de radiólogos y patólogos", o las palabras de un conocido pionero en IA quien dijo "debemos parar de entrenar a radiólogos ahora" han contribuido a este ambiente, lo que ha llevado en EE.UU. a una baja en el interés y en la postulación a programas de residencia en radiología. Los detractores de esta visión, en quienes me incluyo, argumentan que las técnicas han sido desarrolladas para tareas puntuales o diagnósticos muy frecuentes y deja afuera cosas tales como la interpretación del valor clínico de hallazgos sutiles dependiendo del contexto del paciente.

Es en este ambiente en que la comunidad radiológica académica, la que ha tenido que adaptarse a múltiples cambios tecnológicos (digitalización de las imágenes, uso de PACS, post proceso, nuevas técnicas de TC y RM, etc), ha tomado un rol cada vez más activo en el desarrollo de un ecosistema armónico entre la IA y la radiología. Es así como el tema central del congreso de la RSNA el 2018 fue la IA, y la revista Radiology sacó una versión de Radiology: Artificial Intelligence dedicada al tema. En estas instancias y plataformas es donde temas como la incorporación de IA al trabajo diario del radiólogo como un agente facilitador de aspectos más rutinarios como mediciones, co-registro de imágenes para seguimiento e incluso revisión de informes para evitar errores de lateralidad o simplemente faltas en redacción u ortografía, son vistas como una realidad bastante más plausible y deseable, similar a lo que fue el desarrollo del piloto automático en la aviación. Las implicancias éticas de la masificación del uso de IA han aparecido también como una preocupación en el último tiempo, centrado en los principios de seguridad, explicabilidad, transparencia y evitación de sesgos como ejes principales, junto con el problema de la "caja negra" (la incapacidad de entender como un output es derivado de un input) y la duda de quien el responsable final del error o de los efectos adversos derivados de una interpretación por IA, los que serán temas fundamentales a considerar en el mediano plazo.

Con estas consideraciones quisiera concluir esta editorial quedándome con la reflexión del Dr. Curtis P. Lanlglotz, “¿Reemplazará la Al a los radiólogos? es la pregunta errada; la respuesta correcta es: los radiólogos que usan IA reemplazarán a aquellos que no".

\section{Lectura recomendada}

1. Langlotz CP. Will Artificial Intelligence Replace Radiologists? Radiology: Artificial Intelligence. 2019 May; 1(3): e190058. 